\title{
Martensitic transformation as an analogue of a detonation process
}

\author{
M.I. Alymov, V.S. Trofimov ${ }^{\dagger}$ E.V. Petrov \\ †pnkv@list.ru
}

ISMAN, Academician Osipyan St. 8, 142432 Chernogolovka, Russia

\begin{abstract}
The paper deals with the wave model of an austenite to martensite transformation in steel, which is an analogue of a shockwave process like detonation where a wave of transformation of austenite to martensite steel propagates along a steel beam. In Kashchenko's monograph a wave model has been developed according to which, at least within individual austenite grains, this transformation takes place in the form of waves moving at a supersonic speed. In the present work, according to our estimates, the known criterium of detonation capacity is fulfilled in the process of austenite to martensite tranfromation. Under normal conditions, austenite density equals $\rho_{a}=8000 \mathrm{~kg} / \mathrm{m}^{3}$ and martensite density $\rho_{m}=7750 \mathrm{~kg} / \mathrm{m}^{3}$, therefore the transformation of austenite to martensite at constant pressure $P=0.1 \mathrm{MPa}$ and temperature $T=300 \mathrm{~K}$ results in an increase of the volume of steel. This releases a latent heat $Q_{P, T}=82000 \mathrm{~J} / \mathrm{kg}$. Therefore, based on these data one can conclude that if this transformation is implemented in a large steel beam, it would take the form of detonation, that is, a motion at a supersonic velocity of a physical-chemical transformation wave, in this case in the form of a wave of phase transition from austenite to martensite. Parameters of such a process for different ratios between the masses of the austenite and martensite steel in the original beam are estimated. The results of theoretical calculations of the parameters of detonation waves in steel at different weight ratios between austenite and martensite steel in the original beam are presented.
\end{abstract}

Keywords: detonation, shock adiabat, martensite, austenite.

\section{Мартенситное превращение как аналог детонационного процесса}

\author{
Алымов М.И., Трофимов В.С. ${ }^{\dagger}$, Петров Е.В. \\ †pnkv@list.ru \\ ФГБУН Институт структурной макрокинетики и проблем материаловедения РАН, ул. Академика Осипьяна 8, \\ 142432, Черноголовка, Россия
}

В работе рассматривается волновая модель протекающего в стали превращения аустенита в мартенсит как аналог ударно-волнового процесса, подобного детонации, при котором волна превращения аустенита в мартенсит распространяется вдоль бруса стали. В монографии Кащенко М.П. развивается волновая модель, согласно которой, по крайней мере, внутри отдельных зерен аустенита это превращение протекает в виде волн, движущихся со сверхзвуковой скоростью. В данной работе по нашим оценкам, при данном превращении аустенита в мартенсит выполняется известный критерий детонационной способности. При нормальных условиях плотность аустенита $\rho_{a}=8000$ кг $/ \mathrm{M}^{3}$,

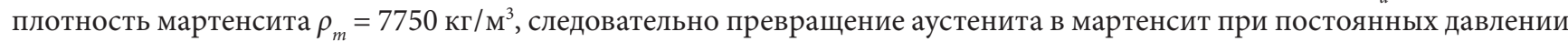
$P=10^{5}$ Па и температуре $T=300 \mathrm{~K}$ приводит к увеличению объема стали. При этом выделяется удельная теплота $Q_{P, T}=82 \times 10^{3}$ Дж/кг. Следовательно, на основании этих данных легко приходим к выводу, что если бы данное превращение удалось реализовать в крупном брусе стали, то оно протекало бы в виде детонации, то есть в виде движения со сверхзвуковой скоростью волны физико-химического превращения, в данном случае в виде волны фазового перехода аустенита в мартенсит. В работе оцениваются параметры такого процесса при разных соотношениях между массами аустенита и мартенсита в исходном брусе стали. Приведены результаты теоретического расчета параметров предполагаемых детонационных волн в стали при разных весовых соотношениях между аустенитом и мартенситом в исходных брусах стали.

Ключевые слова: детонация, ударная адиабата, мартенсит, аустенит. 
В монографии [1] развивается волновая модель протекающего в стали превращения аустенита в мартенсит, согласно которой, по крайней мере, внутри отдельных зерен аустенита это превращение протекает в виде волн, движущихся со сверхзвуковой скоростью. Для сталей определенных химических составов, обладающих макрокинетикой мартенситного превращения (МП) атермического (взрывного) типа, можно ожидать появления макроэффекта формирования волны превращения детонационного типа. Как показал эксперимент [2], возникающие мартенситные кристаллы со сверхзвуковой скоростью пронизывают объем зерна, формируя фронты возмущений, часть из которых обгоняет ударную волну, инициировавшую превращение. Наличие 24 вариантов ориентировок габитусов мартенситных кристаллов и соответствующих путей МП, позволяет ожидать, что в поликристаллических образцах заметная доля ориенировок растущих кристаллов сформирует результирующий фронт, со скоростью меньшей скорости роста отдельных кристаллов. Согласно нашим оценкам, при подобном превращении выполняется известный критерий детонационной способности Н. М. Кузнецова.

В работе [3] этот критерий представлен в двух разных по форме, но физически эквивалентных видах:

$$
Q_{P, V}>0, \quad \Delta V_{P, H}>0,
$$

где: $Q_{P, V}$ - удельная теплота, которая выделилась бы в процессе данного превращения среды, если бы оно началось при нормальных условиях, т.е. при давлении $P=10^{5}$ Па и температуре $T=300 \mathrm{~K}$, и протекло при данном давлении и фиксированном удельном объеме реагирующей среды;

$\Delta V_{P, H}$ - приращение удельного объема вещества при данном превращении среды, если бы оно началось при нормальных условиях и протекло при постоянных давлении и удельной энтальпии $H$, или при постоянном давлении в адиабатических условиях.

Действительно, при давлении $P=10^{5}$ Па и температуре $T=300 \mathrm{~K}$ аустенит находится в метастабильном состоянии. Согласно данным приведенным в работе [4], при нормальных условиях плотность аустенита $\rho_{a}=8000 \mathrm{\kappa г} / \mathrm{M}^{3}$, плотность мартенсита $\rho_{m}=7750 \mathrm{\kappa г} / \mathrm{m}^{3}$. Следовательно, превращение аустенита в мартенсит при постоянных давлении $P=10^{5}$ Па и температуре $T=300 \mathrm{~K}$ приводит к увеличению объема стали. Кроме того, при этом выделяется удельная теплота $Q_{P, T}=82 \times 10^{3}$ Дж/кг $>0$. На основании этих данных легко приходим к выводу, что оба вида критерия (1) выполняются. Следовательно, согласно работе [3], если бы данное превращение удалось реализовать в крупном брусе стали, то оно протекало бы в виде детонации, то есть в виде движения со сверхзвуковой скоростью волны физикохимического превращения, в данном случае в виде волны фазового перехода аустенита в мартенсит.

По аналогии с работой [5] определим параметры этой пока воображаемой детонации.

Запишем в общем виде уравнения ударной адиабаты мартенсита (при начальном удельном объеме мартенсита) и детонационной адиабаты мартенсита (при начальном удельном объеме аустенита):

$$
\begin{aligned}
& E_{m}\left(P_{m}, V\right)-E_{m}\left(P_{0}, V_{m, 0}\right)=\left(P_{m}+P_{0}\right)\left(V_{m, 0}-V\right) / 2, \\
& E_{m}\left(P_{d}, V\right)-E_{a}\left(P_{0}, V_{a, 0}\right)=\left(P_{d}+P_{0}\right)\left(V_{a, 0}-V\right) / 2,
\end{aligned}
$$

где $E_{m}$ и $E_{a}$ - удельные внутренние энергии соответственно мартенсита и аустенита; $P_{m}$ и $P_{d}$ давления соответственно на ударной адиабате и на детонационной адиабате мартенсита (они являются функциями удельного объема $V), V_{m, 0}$ и $V_{a, 0}$ - удельные объемы соответственно мартенсита и аустенита в нормальных условиях.

Вычтем почленно из уравнения (3) уравнение (2) и в полученном выражении сделаем две подстановки.

Первая подстановка:

$$
E_{m}\left(P_{d}, V\right)-E_{m}\left(P_{m}, V\right)=\left(P_{d}-P_{m}\right) V / \Gamma,
$$

где Г - коэффициент Грюнайзена, который считаем постоянным.

По определению:

$$
\Gamma=V\left(\frac{\partial P_{m}}{\partial E_{m}}\right)_{V}=\frac{\beta \alpha^{2}}{C_{P}},
$$

где $\beta$ - коэффициент объемного теплового расширения; $a-$ объемная скорость звука; $C_{P}-$ удельная теплоемкость мартенсита припостоянном давлении.

Вторая подстановка:

$$
E_{a}\left(P_{0}, V_{a, 0}\right)-E_{m}\left(P_{0}, V_{m, 0}\right)=P_{0}\left(V_{m, 0}-V_{a, 0}\right)+Q_{P, T} .
$$

После дальнейших несложных преобразований приходим к уравнению детонационной адиабаты мартенсита в форме $P_{d}(V)$ :

$$
\begin{aligned}
P_{d}(V)-P_{0}=\left(P_{m}(V)-P_{0}\right) \frac{(\Gamma+2) V-\Gamma V_{m, 0}}{(\Gamma+2) V-\Gamma V_{a, 0}}+ \\
+\frac{2 \Gamma Q_{P, T}}{(\Gamma+2) V-\Gamma V_{a, 0}} .
\end{aligned}
$$

Для определения $P_{m}(V)$ в (7) примем приближенную линейную аппроксимацию ударной адиабаты мартенсита в $D-u$ координатах [6]:

$$
D=a+b u,
$$

где $D-$ скорость ударного скачка; $u-$ массовая скорость (скорость ударно сжатой среды относительно среды в исходном состоянии); $a$ и $b-$ константы.

Как обычно, в данном приближении константу $а$ отождествляем с объемной скоростью звука. Из выражения (8), применив законы сохранения массы и импульса при ударном сжатии среды, находим:

$$
P_{m}(V)-P_{0}=a^{2} \frac{V_{m, 0}-V}{\left(V_{m, 0}-b\left(V_{m, 0}-V\right)\right)^{2}} .
$$

Из выражений (7) и (9) определяем зависимость скорости детонационной волны $D$ от $V$ на детонационной адиабате (7):

$$
D(V)=V_{a, 0} \sqrt{\frac{P_{d}(V)-P_{0}}{V_{a, 0}-V}} .
$$

Согласно теории детонации, детонационная волна, как правило, движется с наименьшей скоростью, допускаемой выражением (10). Соответственно находим на детонационной адиабате (7) точку, которой соответствует минимальное значение скорости детонации (10). 
В теории детонации эту точку называют точкой Жуге (Jouguet). Параметры этой точки $V_{J}, P_{J}=P_{d}\left(V_{J}\right)$, вычисляемая по ним скорость детонации $D_{J}=D\left(V_{J}\right)$ и массовая скорость

$$
u_{J}=D_{J} \frac{V_{a, 0}-V_{J}}{V_{a, 0}}
$$

полностью определяют параметры предполагаемой детонационной волны в брусе аустенита.

Выражения (7) - (11) позволяют рассчитать параметры детонационной волны также в брусе стали, состоящем из смеси аустенита и мартенсита. Для этого надо только во все формулы подставить вместо $V_{a, 0}$ и $Q_{P, T}$ соответственно величины $V_{0}$ и $Q_{0}$, определяемые выражениями:

$$
\begin{gathered}
\frac{100}{V_{0}}=\frac{\delta}{V_{a, 0}}+\frac{100-\delta}{V_{m, 0}}, \quad \rho_{0}=\frac{1}{V_{0}}, \\
100 Q_{0}=\delta Q_{P, T} V_{0},
\end{gathered}
$$

где $\delta$ - процентное содержание аустенита в исходном брусе стали.

В таблице 1 приведены результаты расчета параметров предполагаемых детонационных волн в стали при разных весовых соотношениях между аустенитом и мартенситом в исходных брусах стали.

Данные для расчета взяты из [6, 7]: $a=4000 \mathrm{~m} / \mathrm{c}$, $b=1.61, \beta=36 \times 10^{-6} 1 / \mathrm{K}, C_{P}=447$ Дж/(кг $\left.\cdot \mathrm{K}\right)$, согласно (5), $\Gamma=1.3$, модуль Юнга стали $Y=2 \times 10^{11}$ Па, теоретическая прочность $P_{\max }=Y /(2 \cdot \pi)=3.18 \times 10^{10}$ Па.

Полученные данные для скоростей волн превращения в поликристаллической среде показывают, что в ряде случаев (атермическая макрокинетика МП и достаточно крупные зерна исходной фазы) формализм детонационных волн удобно использовать при усредненном макроскопическом описании, не прибегая к статистическим моделям образования результирующего фронта волны превращения.

\section{Заключение}

Относительно реализации рассмотренного процесса в крупных блоках стали в настоящее время возможны только предположения.

Согласно общепринятой теории детонации [6], в любой среде задней границей нормальной стационарной детонационной волны является плоскость Чепме-

Табл. 1. Результаты расчета параметров предполагаемых детонационных волн.

Table 1. The results of calculation of the estimated parameters of detonation waves.

\begin{tabular}{|c|c|c|c|c|c|c|}
\hline$\delta$ & $\begin{array}{c}\rho_{0}, \mathrm{\kappa} / \mathrm{M}^{3} \\
\rho_{0}, \mathrm{~kg} / \mathrm{m}^{3}\end{array}$ & $\begin{array}{c}Q_{0}, 10^{3} \text { Дж/кг } \\
Q_{0}, 10^{3} \mathrm{~J} / \mathrm{kg}\end{array}$ & $\begin{array}{c}D, \mathrm{M} / \mathrm{c} \\
D, \mathrm{~m} / \mathrm{s}\end{array}$ & $\begin{array}{c}u, \mathrm{~m} / \mathrm{c} \\
u, \mathrm{~s}\end{array}$ & $\begin{array}{c}P_{d}, 10^{10} \Pi \mathrm{Ma} \\
P_{d}, 10^{10} \mathrm{~Pa}\end{array}$ & $P_{d} / P_{\max }$ \\
\hline 100 & 8000 & 82 & 5632 & 474 & 2.14 & 0.67 \\
\hline 75 & 7936 & 62 & 5382 & 406 & 1.73 & 0.54 \\
\hline 50 & 7873 & 41 & 5099 & 327 & 1.31 & 0.41 \\
\hline 25 & 7811 & 21 & 4752 & 227 & 0.84 & 0.26 \\
\hline
\end{tabular}

на - Жуге, через которую продукты реакции вытекают со скоростью, равной местной скорости звука. Дальнейшее движение продуктов реакции происходит в форме волны разрежения, передняя граница которой примыкает к плоскости Чепмена - Жуге. Согласно теории, проникание этой волны разрежения внутрь детонационной волны и ее разрушение невозможно. Детонация является самоподдерживающейся.

Однако в теории не учитываются неоднородности конденсированной среды, в частности, границы раздела между зернами. Поэтому при конденсированных продуктах реакции и соответственно при достаточно большом градиенте давления в данной волне разрежения, она, по-видимому, может разрушать детонационную волну и делать невозможной прохождение самоподдерживающейся детонации вдоль крупного блока стали.

Отсюда следует, что для наблюдения детонационного превращения аустенита в мартенсит в крупном блоке стали необходимо исключить волну разрежения, следующую за детонационной волной. Это можно сделать с помощью заряда ВВ, сжимающего образующийся в детонационной волне мартенсит. Однако наблюдаемый процесс уже не будет самоподдерживающимся.

\section{Литература/References}

1. M. P. Kashchenko. The wave model of martensite growth with $\gamma-\alpha$ transformations in iron-based alloys. Textbook. Moscow. SIC «Regular and chaotic dynamics». Izhevsk. Institute of Computer Science. (2010) 280 p. (in Russian) [М. П. Кащенко. Волновая модель роста мартенсита при $\gamma-\alpha$ превращениях в сплавах на основе железа. Москва, НИЦ «Регулярная и хаотическая динамика». Ижевск, Институт компьютерных исследований. 2010. 280 с.]

2. Yu.I. Meshcheryakov, M.P. Kashchenko, V.B. Vasilkov, S.A. Atroshenko, JTP Letters, 19 (2), 75 (1993). (in Russian) [Ю.И. Мещеряков, М.П. Кащенко, В. Б. Васильков, С.А. Атрошенко. Письма в ЖТФ. 19 (2), 75 (1993).]

3. Yu. A. Gordopolov, V.S. Trofimov, A. G. Merzhanov. Reports of the Academy of Sciences. 3 (341), 327 (1995). (in Russian) [Ю.А. Гордополов, В.С. Трофимов, А.Г. Мержанов. Доклады Академии Наук. 3 (341), 327 (1995)].

4. S.E. Krylova, O.A. Kletsova, S.S. Kochkovskaya. Metallurgy and heat treatment of metals. 2 (716), 28 (2015). (in Russian) [C.Е. Крылова, О.А. Клецова, C. С. Кочковская. Металловедение и термическая обработка металлов. 2 (716), 28 (2015)]

5. V.S. Trofimov, V.A. Veretennikov. International Journal of Self-Propagating High-Temperature Synthesis. 4 (23), $240(2014)$

6. L. P. Orlenko. Explosion Physics. Textbook. Moscow. FIZMATLIT. 2 (2004) 656 p. (in Russian) [Л. П. Орленко. Физика взрыва. Москва, ФИЗМАТЛИТ. Т.2. 2004. 656 с.]

7. I.S. Grigor'yev, E.Z. Meylikhov. Physical quantities, reference book. Textbook. Moscow. Energoatomisdat. (1991) 1232 p. (in Russian) [И.С. Григорьев, Е.3. Мейлихов. Физические величины, справочник. Москва, Энергоатомиздат. 1991. 1232 с.] 